\title{
Qualidade da água subterrânea para consumo humano e uso agrícola no sul do estado do Espírito Santo
}

\author{
João Paulo Cunha Menezes', Ana Paula Almeida Bertossi², \\ Alexandre Rosa dos Santos ${ }^{3}$, Mirna Aparecida Neves ${ }^{4}$ \\ 'Universidade Federal de Lavras - Lavras, MG - Brasil \\ ${ }^{2}$ Doutoranda em Produção Vegetal pela Universidade Federal do Espírito Santo - Vitória, ES - Brasil \\ ${ }^{3}$ Professor Associado II da UFES e bolsita CNPq- PQ, nível 2 na Universidade Federal do Espírito Santo - Vitória, ES - Brasil \\ ${ }^{4}$ Professora Adjunta do Departamento de Geologia da Universidade Federal do Espírito Santo, Campus de Alegre (ES) - Brasil
}

\section{Resumo}

A avaliação da qualidade da água é essencial para assegurar o uso sustentável e seguro para consumo humano, uso agrícola e industrial. O objetivo deste trabalho foi avaliar a qualidade da água subterrânea para consumo humano e uso agrícola na zona rural do município de Alegre, localizado no sul do estado do Espírito Santo, onde existem exemplos típicos das pequenas propriedades do interior brasileiro. Foram usados os métodos padrão da APHA para análise de amostras de água subterrânea coletadas em 60 poços tubulares. Foram avaliados alguns parâmetros que influenciam a qualidade da água para consumo humano e irrigação e comparados com os limites legais. A turbidez, o pH, a concentração de ferro e coliformes termotolerantes ficaram acima dos limites permitidos para consumo humano pela portaria do Ministério da Saúde. Não foram identificados problemas de qualidade da água para irrigação com relação à salinidade, entretanto, o uso desta água para irrigação de vegetais que são consumidos crus não é recomendada devido à presença de coliformes termotolerantes.

Palavras-chave: Vigilância sanitária, potabilidade, zona rural, Município de Alegre.

\begin{abstract}
Water quality assessment is needed for ensure sustainable and safe use for drinking, farming and industrial purposes. The aim of this work was to analyze groundwater quality in the countryside of Alegre County, located in the Southern part of Espírito Santo State, which represents a typical example of small farms in the interior of Brazil. Standard methods of APHA were used to analyze water samples from 60 wells. Parameters that influence water quality for drinking and farming purposes were determined and compared with legal thresholds. Values of turbidity, $\mathrm{pH}$, iron and thermo-tolerant coliforms were above permitted limits for drinking purposes of Brazilian Health Ministry's regulation. It was not identified any problem in water quality for irrigation relating to salinity content, however, it is not recommended the use of this water for irrigation of vegetables that are raw consumed due the presence of thermo-tolerant coliforms.
\end{abstract}

Key-words: Sanitary commission, potability, small farm, Alegre County. 


\section{INTRODUÇÃO}

O Estado do Espírito Santo tem sido palco de importante crescimento econômico movido pelas descobertas de novas reservas petrolíferas, pelo aquecimento da indústria de rochas ornamentais e pela expansão das usinas de açúcar e álcool. Este crescimento tem gerado empregos e riquezas, mas também pode causar impactos ambientais indesejáveis como a degradação da qualidade da água. O município de Alegre situa-se no sul do Estado, próximo à Serra do Caparaó, caracterizando um exemplo típico do interior capixaba. A região sul do estado, intensamente explorada pela monocultura do café, atualmente é ocupada em grande parte pela pecuária extensiva (IBGE, 2010), atividades responsáveis pelo desmatamento abusivo ao longo de várias décadas.

As áreas urbanas, embora restritas, têm se tornado mais populosas com a vinda de trabalhadores para construção de pequenas centrais hidrelétricas, abertura e recuperação de estadas, dentre outros empreendimentos. Nestes locais, é comum o lançamento de esgotos in natura, transformando os rios em verdadeiros esgotos a céu aberto. A situação não é diferente das grandes metrópoles brasileiras, guardadas as devidas proporções.

A população da zona rural no município de Alegre é abastecida quase que exclusivamente por água subterrânea. Acreditando tratar-se de um recurso invulnerável, os pequenos agricultores, geralmente desinformados, consomem a água diretamente dos poços, sem nenhum tipo de tratamento. Porém, estes recursos podem representar um risco à saúde humana por estarem mais expostos às ações antrópicas, ainda que em áreas pouco povoadas.

Outro uso importante da agua subterrânea na zona rural de Alegre é o uso na irrigação. $\mathrm{O}$ clima da região vem sofrendo alterações em consequência das mudanças globais, sendo que alguns indícios de desertificação já foram registrados no norte do estado. Assim, o uso da água subterrânea para irrigação em pequena escala deverá se tornar importante alternativa para sustentar a vida no campo em futuro próximo.

O conhecimento da constituição iônica da água é primordial para avaliar sua adequabilidade ao consumo humano (BRASIL, 2008; 2011) ou para uso na irrigação (AYERS e WESTCOT, 1999; ALMEIDA, 2010). Nos países em desenvolvimento, em virtude das precárias condições de saneamento e da má qualidade das águas, as doenças de veiculação hídrica têm sido responsáveis por surtos epidêmicos e elevadas taxas de mortalidade infantil, o que torna primordial a avaliação microbiológica da água consumida (ISSAC-MARQUEZ, 1994). Outro parâmetro importante a ser analisado é a concentração de nitrato. O seu consumo por meio da água está associado a dois efeitos adversos à saúde: indução à metahemoglobinemia, especialmente em crianças, e a formação potencial de nitrosaminas e nitrosamidas carcinogênicas (BOUCHARD, 1992).

Em relação ao uso na agricultura, Ayers e Westcot (1999) destacam que os problemas relacionados com a salinidade das águas são os principais, pois o excesso de sais solúveis no solo reduz a disponibilidade de água para as plantas, que pode causar problemas de impermeabilização nos solos e toxidez por alguns íons específicos (KUMAR et al., 2007; NAGARAJAN et al., 2010; REDDY e KUMAR, 2010).

Desta forma, a avaliação da qualidade da água torna-se uma importante ferramenta para efetivar a gestão dos recursos hídricos. Durante os pulsos de desenvolvimento econômico, é importante voltar atenção para a fixação do homem no campo, de forma a dirimir o crescimento populacional das cidades. Diante da importância do uso da água subterrânea em propriedades rurais no sul capixaba e o aumento da demanda para irrigação, apresenta-se, neste trabalho, uma avaliação da qualidade da água subterrânea utilizada para estes fins no município de Alegre, localizado no sul do Estado do Espírito Santo.

\section{MATERIAL E MÉTODOS}

\section{I Área de Estudo}

O município de Alegre abrange $773 \mathrm{~km}^{2}$ no extremo Sul do Estado do Espírito Santo (Figura 1 ), entre as coordenadas geográficas $41^{\circ} 30^{\prime} 0^{\prime \prime}$ e $41^{\circ} 39^{\prime} 0^{\prime \prime}$ de longitude Oeste e $20^{\circ} 30^{\prime} 0^{\prime \prime} \mathrm{S}$ e 205' $30^{\prime \prime}$ latitude Sul. Segundo a classificação de Köppen, o clima da região é do tipo "Cwa", isto é, tropical quente e úmido, com inverno frio e seco e verão chuvoso. A temperatura anual média é de $23,1^{\circ} \mathrm{C}$ e a precipitação total anual média é de $1341 \mathrm{~mm}$. De maneira geral, a topografia da região possui relevo bastante acidentado, com reduzidas áreas planas (IBGE, 2010).

O Sistema Aquífero Cristalino e o Aquífero Cenozóico, representado por depósitos aluviais quaternários, são os mananciais existentes na área. A água presente no manto de intemperismo dos gnaisses e rochas granitoides tem grande 

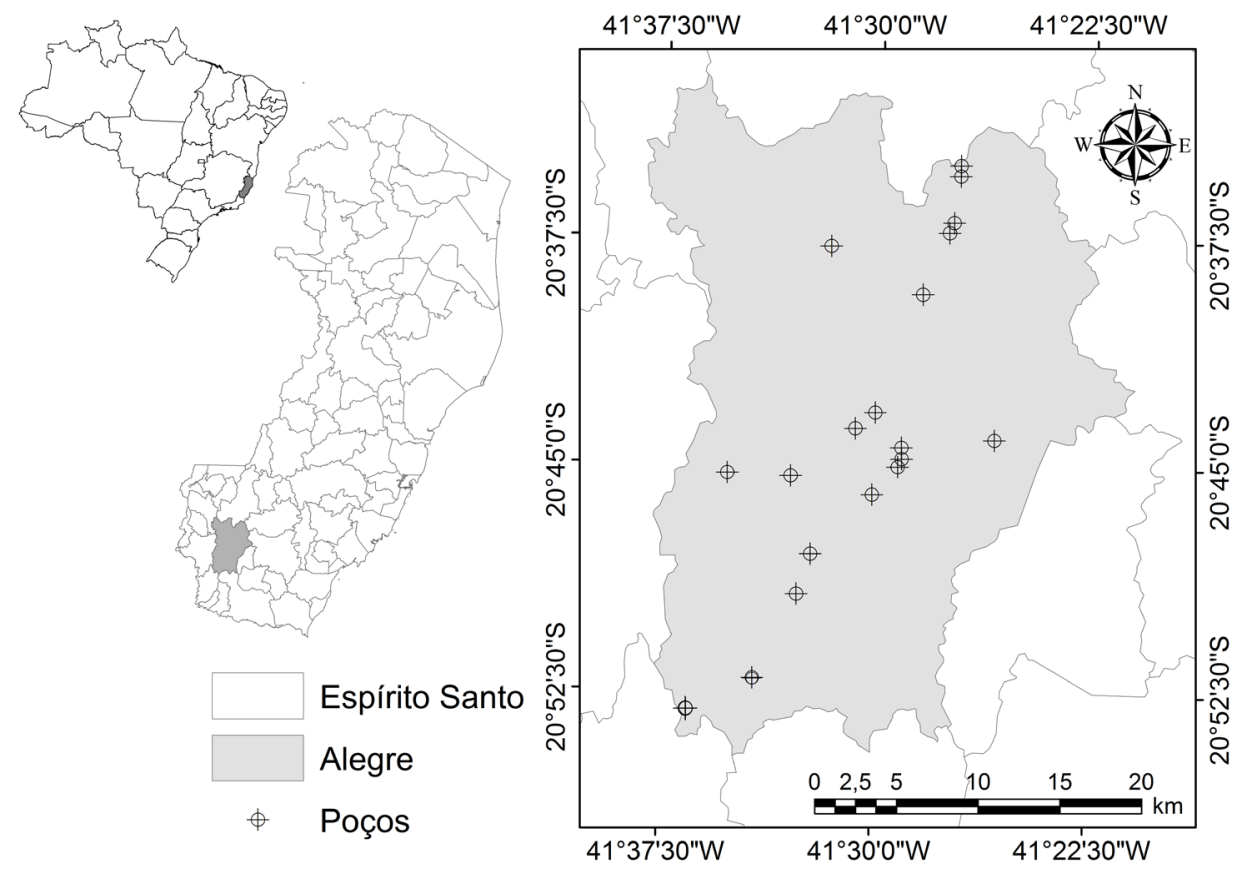

Figura 1 - Localização da área de estudo e dos pontos de coleta de água subterrânea.

importância neste contexto, pois, para abastecimento doméstico e irrigação em pequena escala, as pequenas vazões ali encontradas são suficientes.

O Sistema Aquífero Cristalino e o Aquífero Cenozóico, representado por depósitos aluviais quaternários, são os mananciais existentes na área. A água presente no manto de intemperismo dos gnaisses e rochas granitoides tem grande importância neste contexto, pois, para abastecimento doméstico e irrigação em pequena escala, as pequenas vazões ali encontradas são suficientes.

\subsection{Coleta das Amostras}

Foram coletadas amostras em vinte poços de abastecimento (Figura 1) para análise física, química e microbiológica, no mês de fevereiro de 2011. Os poços, com profundidade média de $18 \mathrm{~m}$, explotam o manto de intemperismo que compõe o Sistema Aquífero Cristalino na região. Para cada ponto de coleta, realizou-se 3 replicações das medidas a fim de conduzir uma maior confiabilidade aos parâmetros analisados. As amostras foram coletadas em garrafas de polietileno com volume de $2 \mathrm{~L}$, devidamente higienizadas e secas. Para as análises de nitrato, fósforo e coliformes, as amostras foram coletadas em garrafas de vidro de $250 \mathrm{~mL}$ previamente esterilizadas. As amostras foram rotuladas e refrigeradas a $4^{\circ} \mathrm{C}$ até serem levadas ao laboratório, seguindo a orientação da NBR 9898 e do "Standard methods for the examination of water and wastewater" (ABNT, 1987; APHA, 2005).
Os dados de campo foram coletados com medidor multiparâmetro para $\mathrm{pH}, \mathrm{CE}$ e temperatura, além de um turbidímetro portátil. Em laboratório, foram analisados os sólidos em suspensão (SS), sólidos totais dissolvidos (STD), cátions $\left(\mathrm{B}^{+3}\right.$, $\left.\mathrm{Ca}^{+2}, \mathrm{~K}^{+}, \mathrm{Mg}^{+2}, \mathrm{Na}^{+}, \mathrm{P}\right)$ e ânions $\left(\mathrm{HCO}_{3}^{-}, \mathrm{NO}_{2}^{-}\right.$, $\mathrm{NO}_{3}-$ ), além de coliformes totais e termotolerantes. Utilizou-se o método do "Standard methods for the examination of water and wastewater" (APHA, 2005). A partir desses parâmetros, foi possível estimar algumas variáveis secundárias: porcentagem de sódio, razão de adsorção de sódio e dureza (AYERS e WESTCOT, 1999; ALMEIDA, 2010; SAWYER e MC CARTHY, 1967). O software estatístico usado para análise descritiva dos dados foi o R-cram, versão 2.14.0. Para geração do mapa de localização dos poços foi utilizado o software ArcGis ${ }^{\circledR} 10$ (ESRI, 2011).

\section{RESULTADOS E DISCUSSÃO}

Os valores obtidos para os parâmetros de qualidade da água que afetam sua adequação para consumo humano estão apresentados na Tabela 1 , juntamente com os padrões de potabilidade e limites estabelecidos pelo Ministério da Saúde, Conselho Nacional de Meio Ambiente e World Health Organization (BRASIL, 2008; 2011; WHO, 2006). Observa-se que há grande variabilidade de valores na maioria dos parâmetros e que a turbidez, o $\mathrm{pH}, \mathrm{Fe}^{+3}$, bicarbonato e coliformes apresentaram 
Tabela 1 - Descritores estatísticos das variáveis indicadoras de qualidade de água subterrânea para consumo humano e sua comparação com os limites estabelecidos pelo Ministério da Saúde (BRASIL, 2011)

\begin{tabular}{|c|c|c|c|c|c|}
\hline \multirow{2}{*}{ PARÂMETROS } & \multicolumn{4}{|c|}{ ESTATISTICA DESCRITIVA } & \multirow{2}{*}{$\begin{array}{c}\text { PADRÕES } \\
\text { Portaria } \\
2.914 / 2011\end{array}$} \\
\hline & Unidade & $\begin{array}{l}\text { Valores } \\
\text { Mínimos }\end{array}$ & $\begin{array}{l}\text { Média } \pm \text { desvio } \\
\text { padrão }\end{array}$ & $\begin{array}{l}\text { Valores } \\
\text { Máximos }\end{array}$ & \\
\hline \multicolumn{6}{|c|}{ Parâmetros Físicos } \\
\hline Temperatura & ${ }^{\circ} \mathrm{C}$ & 19,20 & $22,51 \pm 2,20$ & 28,90 & NPD \\
\hline Turbidez & UNT & 0 & $19,31 \pm 77,18$ & 378,00 & 5 \\
\hline Sol. Suspensão & $\mathrm{mg} \mathrm{L}^{-1}$ & 1,90 & $66,55 \pm 98,90$ & 407,10 & NPD \\
\hline \multicolumn{6}{|c|}{ Parâmetros Químicos } \\
\hline $\mathrm{CE}$ & $\mathrm{dS} \mathrm{m}^{-1}$ & 0,03 & $0,14 \pm 0,08$ & 0,34 & NPD \\
\hline $\mathrm{pH}$ & & 5,00 & $6,16 \pm 0,39$ & 6,90 & $6,0-9,0$ \\
\hline STD & $\mathrm{mg} \mathrm{L}^{-1}$ & 1,50 & $76,09 \pm 51,21$ & 186,70 & 1000 \\
\hline $\mathrm{Na}^{+}$ & $\mathrm{mg} \mathrm{L}^{-1}$ & 2,30 & $11,33 \pm 6,53$ & 26,70 & 200 \\
\hline $\mathrm{K}^{+}$ & $m g \mathrm{~L}^{-1}$ & 0,50 & $4,75 \pm 7,33$ & 35,80 & $55^{* *}$ \\
\hline $\mathrm{Ca}^{+2}$ & $\mathrm{mg} \mathrm{L}^{-1}$ & 0 & $0,02 \pm 0,21$ & 1,00 & $75 * *$ \\
\hline $\mathrm{Mg}^{+2}$ & $\mathrm{mg} \mathrm{L}^{-1}$ & 0,18 & $0,89 \pm 0,89$ & 4,09 & $50 * *$ \\
\hline $\mathrm{Fe}^{+3}$ & $\mathrm{mg} \mathrm{L}^{-1}$ & 0 & $0,02 \pm 0,07$ & 0,34 & 0,3 \\
\hline $\mathrm{HCO}_{3}^{-}$ & mg L-1 & 4,88 & $39,75 \pm 22,77$ & 78,08 & $1000 * *$ \\
\hline $\mathrm{NO}_{2}^{-}$ & $\mathrm{mg} \mathrm{L}^{-1}$ & 0,00 & $0,01 \pm 0,03$ & 0,16 & 1 \\
\hline $\mathrm{NO}_{3}^{-}$ & $\mathrm{mg} \mathrm{L}^{-1}$ & 0,01 & $0,32 \pm 0,24$ & 0,79 & 10 \\
\hline $\mathrm{B}^{+3}$ & $m g \mathrm{~L}^{-1}$ & 0,00 & $0,08 \pm 0,10$ & 0,26 & $0,5^{*}$ \\
\hline Fósforo Total & $m g \mathrm{~L}^{-1}$ & 0,01 & $0,11 \pm 0,10$ & 0,41 & NPD \\
\hline \multicolumn{6}{|c|}{ Parâmetros Microbiológicos } \\
\hline $\begin{array}{l}\text { Coliformes } \\
\text { Totais }\end{array}$ & $\begin{array}{l}\text { NMP } \\
100 \mathrm{ml}\end{array}$ & 4 & $218,30 \pm 379,53$ & 1100 & $\begin{array}{c}\text { Ausência em } \\
100 \mathrm{ml}\end{array}$ \\
\hline $\begin{array}{l}\text { Coliformes } \\
\text { Termotolerantes }\end{array}$ & $\begin{array}{l}\text { NMP } \\
100 \mathrm{ml}\end{array}$ & 3 & $42,90 \pm 67,47$ & 240 & $\begin{array}{l}\text { Ausência em } \\
100 \mathrm{ml}\end{array}$ \\
\hline
\end{tabular}

valores acima do permitido para consumo humano. Em relação à temperatura, as amostras analisadas apresentaram uma média de $22,5^{\circ} \mathrm{C}$, variando de 19,2 a $28,9^{\circ} \mathrm{C}$. A variação encontrada pode ser justificada pelas diferentes profundidades dos poços, pois, em aquíferos freáticos, poços mais profundos tendem a apresentar temperatura menor em relação a poços menos profundos (Feitosa e Manoel Filho, 2000).

Os sólidos em suspensão ou sólidos não filtráveis correspondem aos materiais em suspensão do tipo coloides, entre outros (FEITOSA e MANOEL FILHO, 2000). Nas amostras analisa- das, obteve-se uma média de $66,5 \mathrm{mg} \mathrm{L}^{-1}$ variando de 1,9 a $407,1 \mathrm{mg} \mathrm{L}^{-1}$ (Tabela 1), entretanto, tais valores podem ser considerados elevados para águas subterrâneas, já que o solo funciona como um filtro que retém o material particulado (FEITOSA e MANOEL FILHO, 2000). Possivelmente, os valores elevados estão relacionados ao mau dimensionamento do filtro ou pré-filtro, o que facilitaria a passagem de partículas. Outro indício de problemas construtivos nos poços observa-se nos resultados da turbidez com valor médio de 19,3 UNT, variando de 0 a 378 UNT. Dentre as amostras analisadas, $15 \%$ ficaram fora do padrão 
de potabilidade estabelecido pelo Ministério da Saúde (BRASIL, 2011). Vale salientar que, geralmente, as águas subterrâneas têm baixos valores de turbidez, devido ao efeito filtro do solo (FEITOSA e MANOEL FILHO, 2000; OBIEFUNA e SHERIFF, 2011).

Quanto aos sólidos totais dissolvidos (STD), nenhuma das amostras analisadas ultrapassou o valor máximo de $1.000 \mathrm{mg} \mathrm{L}^{-1}$ estabelecido pela Portaria $n^{\circ}$. 2.914 de potabilidade do Ministério do Meio Ambiente. Os valores obtidos variaram de 1,50 mg L-1 a 186,70 $\mathrm{mg} \mathrm{L}^{-1}$, com média de 76,09 $\mathrm{mg} \mathrm{L}^{-1}$ (Tabela 1). Os STD representam a concentração de todo o material dissolvido na água, seja ele de natureza iônica ou coloidal. O teor de sais dissolvidos exclusivamente sob a forma de íons foi avaliada através da Condutividade Elétrica (CE). A CE média das águas subterrâneas analisadas foi de $0,14 \mathrm{dS} \mathrm{m}^{-1}$, variando de 0,03 a $0,34 \mathrm{dS}$ $\mathrm{m}^{-1}$ (Tabela 1), o que indica a existência de baixa concentração de sais dissolvidos. Entretanto, não são feitas referências diretas a esse parâmetro na legislação no que diz respeito ao consumo humano.

A água subterrânea amostrada apresentou variação de $\mathrm{pH}$ de 5,0 a 6,9. A Portaria $\mathrm{n}^{\circ} 2.914$ do Ministério da Saúde (Brasil, 2011) estabelece que o $\mathrm{pH}$ da água destinada ao abastecimento humano deve situar-se entre 6,0 e 9,0 (Tabela 1). Do total das amostras coletadas, 18,33\% apresentaram-se impróprias para consumo humano, estando abaixo da faixa estabelecida. Os baixos valores de $\mathrm{pH}$ podem ser atribuídos à presença de vários fatores, tais como concentrações de $\mathrm{CO}^{2}$, oxidação da matéria orgânica, temperatura da água, entre outros. Embora a maior parte das amostras apresentem o $\mathrm{pH}$ dentro da faixa recomendada, parte da comunidade está consumindo água não potável em relação a este parâmetro, representando risco à saúde humana.

A concentração do $\mathrm{Na}^{+}$nas águas subterrâneas varia entre 0,1 e $100 \mathrm{mg} \mathrm{L}-1$ (FEITOSA e MANOEL FILHO, 2000). Nas águas estudadas, as concentrações de $\mathrm{Na}^{+}$apresentaram concentração entre 2,30 e 26,70 $\mathrm{mg} \mathrm{L}^{-1}$ com média de 11,33 $\mathrm{mg} \mathrm{L}^{-1}$ (Tabela 1), estando portanto de acordo com o padrão de potabilidade estabelecido pela legislação vigente (BRASIL, 2008; 2011). O íon $\mathrm{Na}+$ é altamente móvel no ambiente e está presente em todas as águas, como enfatizado por vários autores, entre eles Percebon e Bittencourt (2009) e Obiefuna e Sheriff (2011). Esse íon é o principal responsável pelo aumento constante da salinidade das águas naturais do ponto de vista catiônico. Há, em geral, um aumento gradativo dos teores de $\mathrm{Na}^{+}$nas águas subterrâneas, a partir da zona de recarga, em direção às suas porções mais confinadas.

A concentração média do íon $\mathrm{K}^{+}$nas águas dos poços foi de $4,75 \mathrm{mg} \mathrm{L}^{-1}$, variando de 0,50 a $35,80 \mathrm{mgL}^{-1}$ (Tabela 1 ). O teor médio de $\mathrm{K}^{+}$é inferior ao de $\mathrm{Na}^{+}$; apesar de ambos pertencerem ao grupo dos metais alcalinos, seus comportamentos são diferentes nos processos de solubilização (OBIEFUNA e SHERIFF, 2011). O íon $\mathrm{K}^{+}$é facilmente removido da água por meio de troca iônica na adsorção por argilas e absorção pelas plantas. Em geral, os teores de $\mathrm{K}^{+}$nas águas subterrâneas são inferiores a $10,0 \mathrm{mg} \mathrm{L}^{-1}$, sendo mais frequentes valores entre 1,0 e $5,0 \mathrm{mg} \mathrm{L}^{-1}$ (FEITOSA e MANOEL FILHO, 2000; OBIEFUNA e SHERIFF, 2011). Apesar de não existir limite estabelecido pela Portaria $n^{\circ} 2.914$ do Ministério da Saúde3 para a concentração de $\mathrm{K}^{+}$, adotou-se o valor de $55 \mathrm{mg} \mathrm{L}^{-1}$, sugerido pela Organização Mundial da Saúde (WHO, 2006) para a avaliação dos resultados expostos. Nesta avaliação, os índices ficaram abaixo do limite para todas as amostras, dentro dos valores de potabilidade.

Em águas subterrâneas, os teores de $\mathrm{Ca}^{+2}$ oscilaram entre 10 e $100 \mathrm{mg} \mathrm{L}^{-1}$ (OBIEFUNA e SHERIFF, 2011). Para as amostras analisadas, o teor de $\mathrm{Ca}^{+2}$ variou de 0 a $1 \mathrm{mg} \mathrm{L}^{-1}$, com média de $0,02 \mathrm{mg} \mathrm{L}^{-1}$ (Tabela 1 ). $\mathrm{O} \mathrm{Ca}^{+2}$ contribui para dureza da água e é considerado um dos elementos mais comuns e abundantes na maioria das águas. Já $\mathrm{o} \mathrm{Mg}^{+2}$ possui propriedades similares às do $\mathrm{Ca}^{+2}$, porém é mais solúvel e mais difícil de precipitar. As águas subterrâneas apresentam normalmente valores de $\mathrm{Mg}^{+2}$ no intervalo de $1 \mathrm{a}$ $40 \mathrm{mg} \mathrm{L}^{-1}$ (OBIEFUNA e SHERIFF, 2011). No presente estudo, as amostras apresentaram valores entre 0,18 e 4,09 $\mathrm{mg} \mathrm{L}^{-1}$, com média de $0,89 \mathrm{mg}$ $\mathrm{L}^{-1}$ (Tabela 1).

$\mathrm{O} \mathrm{Fe}^{+3}$ está presente em quase todas as águas, mas em baixa concentração $(<0,3 \mathrm{mg}$ $\left.\mathrm{L}^{-1}\right)$. Geralmente, ele ocorre sob a forma de $\mathrm{Fe}^{+3}$, podendo também ocorrer como $\mathrm{Fe}^{+2}$ (hidróxido ferroso). $\mathrm{O} F e$ na forma de $\mathrm{Fe}^{+2}$ é muito instável na presença de oxigênio, mudando para o estado férrico (OBIEFUNA e SHERIFF, 2011). Nos pontos avaliados, apenas um poço apresentou $\mathrm{Fe}^{+3} \mathrm{em}$ suas águas, com média de $0,33 \mathrm{mg} \mathrm{L}^{-1}$ (Tabela 1 ).

A origem do bicarbonato nas águas subterrâneas está relacionada principalmente aos processos que produzem o gás carbônico no solo por meio da decomposição e oxidação da matéria orgânica e à respiração das raízes das plantas (OBIEFUNA e SHERIFF, 2011). A dissolução do $\mathrm{CO}_{2}$ na água forma o ácido carbônico $\left(\mathrm{H}^{2} \mathrm{CO}^{3}\right)$, que se dissocia em $\mathrm{H}^{+}$e $\mathrm{HCO}_{3}$. A concentração 
de $\mathrm{HCO}_{3}$ - na água subterrânea varia entre 50 e 350 $\mathrm{mg} \mathrm{L}^{-1} \mathrm{em}$ águas doces, podendo chegar a $800 \mathrm{mg}$ L-1 (FEITOSA e MANOEL FILHO, 2000; OBIEFUNA e SHERIFF, 2011). Nas águas analisadas, o valor médio de $\mathrm{HCO}_{3}{ }^{-}$obtido foi de $39,75 \mathrm{mg} \mathrm{L}^{-1}$ $\mathrm{HCO}_{3}^{-}$, variando entre 4,88 e $78,08 \mathrm{mg} \mathrm{L}^{-1}$.

Dos 20 poços estudados, apenas 6 (seis) poços apresentaram valores superiores ao limite de detecção para o $\mathrm{NO}_{2}^{-}$, sendo estas com concentrações muito baixas, variando entre 0,00 a $0,16 \mathrm{mg}$ $\mathrm{L}^{-1}$ (Tabela 1). $\mathrm{O}$ valor médio de $\mathrm{NO}_{3}{ }^{-}$nas águas dos poços foi de $0,32 \mathrm{mg} \mathrm{L}^{-1}$, sendo 0,01 e 0,79 $\mathrm{mg} \mathrm{L^{-1 }}$ os valores mínimos e máximos, respectivamente (Tabela 1 ).

$\mathrm{O} \mathrm{NO}_{3}^{-}$ocorre geralmente em baixas concentrações na água subterrânea, representando o estágio final da oxidação da matéria orgânica. Os tipos de rocha presentes na área não influenciam na variação do teor desse íon e sua elevação nas águas subterrâneas indica influência de fontes de contaminação antrópicas, possivelmente por fertilizantes ou por fossa séptica. Contudo, os teores encontrados não foram elevados, já que a contaminação, neste caso, caracteriza-se por concentrações acima de $10 \mathrm{mg} \mathrm{L}^{-1}$ de $\mathrm{NO}_{3}^{-}$(BRASIL, 2011). Em condições aeróbias, considera-se normais valores de nitratos na faixa de 4 a $9 \mathrm{mg}$ $\mathrm{L}^{-1}$ (WHO, 2006). A aplicação de dejetos animais para adubação do solo, associada à prática da irrigação nas áreas agricultadas, provavelmente foi a principal fonte da entrada desse nutriente no sistema, supondo-se que ocorra escoamento superficial e subsuperfícial da substância.

O boro nas águas subterrâneas pode ser encontrado na forma de $\mathrm{H}_{3} \mathrm{BO}_{3}$ ou parcialmente dissociado em $\mathrm{H}_{2} \mathrm{BO}_{3}^{-}$, apresentando geralmente valores inferiores a $0,1 \mathrm{mg} \mathrm{L}^{-1}$, mas podendo chegar a $10 \mathrm{mg} \mathrm{L}^{-1}$. É considerado como pouco prejudicial à saúde humana, mas pode ser tóxico para os vegetais quando a concentração é elevada (FEITOSA e MANOEL FILHO, 2000). A concentração média de $\mathrm{B}^{+3}$ nas amostras foi de $0,08 \mathrm{mg} \mathrm{L}^{-1}$, variando de 0,00 a $0,26 \mathrm{mg} \mathrm{L}^{-1}$ (Tabela 1 ). Valores estes abaixo do valor máximo permitido para consumo humano, que é de $0,5 \mathrm{mg} \mathrm{L}^{-1}$ (BRASIL, 2008).

O fósforo possui uma tendência para formar compostos com vários íons e coligações com os minerais de argila. Devido a esse fato, suas concentrações nas águas subterrâneas são baixas, variando geralmente entre 0,01 e $1 \mathrm{mg} \mathrm{L}^{-1}$ (FEITOSA e MANOEL FILHO, 2000) Nas amostras analisadas, os valores estiveram entre 0,01 e 0,41 $\mathrm{mg} \mathrm{L}^{-1}$, com uma média de $0,11 \mathrm{mg} \mathrm{L}^{-1}$.

Todos os 20 poços analisados apresentaram coliformes totais e termotolerantes. Para os coli- formes totais obteve-se o valor médio de 218,30 NMP $100 \mathrm{~mL}^{-1}$, variando de 4 a 1100 NMP 100 $\mathrm{mL}-1$, enquanto para os termotolerantes a média foi de 42,90 NMP $100 \mathrm{~mL}^{-1}$, variando de 3 a 240 NMP. Dessa forma, $100 \%$ das amostras coletadas estavam em desacordo com o preconizado pela Portaria $\mathrm{n}^{\circ}$ 2.914/2011 do Ministério da Saúde em relação ao padrão microbiológico de coliformes termotolerantes. O Ministério da Saúde tolera a presença de coliformes totais somente na ausência de Escherichia coli e/ou coliformes termotolerantes. A presença de coliformes nas águas analisadas pode ser explicada pelas más condições de construção dos poços e pela proximidade de fossas sépticas e currais. A deposição diária de resíduo orgânico animal no solo, prática muito disseminada no meio rural, aumenta o risco da contaminação das águas subterrâneas. As águas contaminadas podem se tornar um meio de cultura ideal, conforme as condições de $\mathrm{pH}$, temperatura, partículas minerais, material dissolvido e matéria orgânica presentes, elementos essenciais que a biocenose necessita para seu desenvolvimento.

Segundo Bonilha e Falcão (2003), a utilização de água de má qualidade na irrigação pode influenciar a salubridade das hortaliças, principalmente em relação à presença de coliformes. A irrigação de hortaliças com água contaminada torna-se veículo de transmissão de patógenos, sobretudo aquelas que são ingeridas sem qualquer tratamento térmico (BONILHA e FALCÃO, 2003).

\section{I Avaliação da qualidade da água subterrânea para uso na agricultura}

Os aspectos essenciais ao analisar o uso da água para irrigação são aqueles que comprometem principalmente a conservação do solo e o rendimento e qualidade das colheitas. A qualidade da água para fins agrícolas é definida em função dos critérios de salinidade, sodicidade, toxicidade e outros (ALMEIDA, 2010). Neste contexto, foram utilizados, neste trabalho: critérios de salinidade (risco de salinidade); critérios de sodicidade (relação de adsorção de sódio - RAS); critérios de toxicidade; risco de boro (ou concentração de boro) e dureza.

A classificação da água subterrânea com base no perigo de salinidade é apresentada na Tabela 2.

Todas as amostras de água analisadas na região foram classificadas como pertencentes às classes 1 e 2 , podendo ser consideradas adequadas para irrigação. Águas classificadas como de baixa salinidade $\left(C_{1}\right)$ podem ser usadas para irrigação da maioria das culturas e na maioria dos solos, com 
Tabela 2. Classificação da água subterrânea no município de Alegre (ES) quanto ao risco de salinidade, utilizando critérios do USSL (ALMEIDA, 2010)

\begin{tabular}{llll}
\hline $\mathbf{C E}\left(\mathbf{d S ~ m}^{-1}\right)$ & Classes de perigo de salinidade & Qualidade & $\mathbf{n}^{\mathbf{0}}$ amostras \\
\hline $0-0,25$ & $\mathrm{C}_{1}$ & Excelente & $51(85 \%)$ \\
$0,25-0,75$ & $\mathrm{C}_{2}$ & Boa & $09(15 \%)$ \\
$0,75-2,25$ & $\mathrm{C}_{3}$ & Duvidosa & 0 \\
$>2,25$ & $\mathrm{C}_{4} \mathrm{e}_{5}$ & Inadequada & 0 \\
\hline
\end{tabular}

probabilidade muito baixa de que se desenvolva salinidade. As amostras com média salinidade $\left(\mathrm{C}_{2}\right)$ podem ser usadas, desde que ocorra uma quantidade moderada de lixiviação. Águas com alta concentração de sais $\left(\mathrm{C}_{3}\right)$ são adequadas apenas para poucas culturas que possuem tolerância, enquanto as águas com salinidade muito alta $\left(\mathrm{C}_{4}\right.$ e $C_{5}$ ), de forma geral, são inadequadas para irrigação, podendo ser usada apenas ocasionalmente em circunstâncias muito especiais (PURUSHOTHAM et al. 2011).

Esta classificação tem como finalidade diagnosticar e classificar a concentração total de sais solúveis na água para fins de irrigação com base na condutividade elétrica. A salinização nas terras irrigadas é a principal causa de perda de produção, e tem impactos ambientais adversos. Condições salinas limitam severamente a escolha das culturas e afetam negativamente a germinação e o rendimento, reduzindo a atividade osmótica das plantas e interferindo na absorção de água e nutrientes do solo (PURUSHOTHAM et al. 2011).

Outro fator importante para avaliar a qualidade da água usada na irrigação refere-se às relações entre a concentração de $\mathrm{Na}^{+}, \mathrm{Ca}^{+2} \mathrm{e} \mathrm{Mg}^{+2}$, usando-se para isso a Razão de Adsorção de Sódio (RAS). A RAS constitui um critério importante para determinar a adequação da água para irrigação, já que teores de $\mathrm{Na}^{+}$excessivos em relação aos de $\mathrm{Ca}^{+2}$ e $\mathrm{Mg}^{+2}$ reduzem a permeabilidade do solo e, portanto, inibem a oferta de água necessária para as culturas. A RAS pode ser calculada pela Equação 1.

$$
R A S=\frac{N a^{+}}{\sqrt{\frac{\left(C a^{+2}+M g^{+2}\right)}{2}}}
$$

Equação 1

Em que,

RAS é a Razão de Adsorção de Sódio e as concentrações são expressas em milimol por litro.

A classificação das amostras de água subterrânea da área de estudo com relação à RAS está apresentada na Tabela 3. Todas as amostras apresentaram valor inferior a 10 , sendo classificadas desta forma como excelentes para a irrigação (categoria $\mathrm{S}^{1}$ ).

Quanto aos critérios de toxicidade, as concentrações de Boro na água subterrânea ficaram entre 0,00 e $0,26 \mathrm{mg} \mathrm{L}^{-1}$, com um valor médio de $0,08 \mathrm{mg} \mathrm{L}^{-1}$. Dos limites propostos para a concentração de boro na água de irrigação, todas as amostras apresentaram-se dentro da faixa permitida (Tabela 4), sendo classificadas como excelentes para culturas tolerantes e semitolerantes ao Boro.

Ao determinar a adequação das águas subterrâneas para uso doméstico ou para irrigação, a dureza também é um critério importante a ser considerado. A dureza total (DT, em ppm) foi determinada seguindo a Equação 2 .

$$
D T=2,497 \mathrm{Ca}^{+2}+4,115 \mathrm{Mg}^{+2} \quad \text { Equação } 2
$$

Em que,

DT é a dureza total e as quantidades dos elementos são expressas em miliequivalentes por litro.

Tabela 3. Adequação da qualidade da água subterrânea do município de Alegre (ES) de acordo com a RAS e as classes de risco de sódio, conforme classificação da USSL (ALMEIDA, 2011).

\begin{tabular}{llll}
\hline Valores da RAS & Classes de perigo de sódio & Qualidade & $\mathbf{n}^{\mathbf{0}}$ amostras \\
\hline$<10$ & S1 & Excelente & $60(100 \%)$ \\
$10-18$ & S2 & Boa & 0 \\
$19-26$ & S3 & Duvidoso & 0 \\
$>26$ & S4 e S5 & Inadequado & 0 \\
\hline
\end{tabular}


Tabela 4. Classificação da água subterrânea do município de Alegre (ES) com base nos teores de Boro para irrigação em vários tipos de cultura (adaptado de McCarthy e Ellery (1994)).

\begin{tabular}{lllll}
\multicolumn{1}{c}{ Classes de } & \multicolumn{2}{c}{ Culturas sensíveis } & \multicolumn{2}{c}{ Culturas semi tolerantes e tolerantes } \\
\cline { 2 - 5 } \multicolumn{1}{c}{ Boro } & \multicolumn{1}{c}{$\mathrm{mg} \mathrm{L}^{-1}$} & \multicolumn{1}{c}{$\%$ de amostras } & \multicolumn{1}{c}{$\mathrm{mg} \mathrm{L}^{-1}$} & \multicolumn{1}{c}{$\%$ de amostras } \\
\hline Excelente & $<0,33$ & 100 & $<0,67$ & $60(100 \%)$ \\
Boa & $0,33-0,67$ & 0 & $0,67-1,33$ & 0 \\
Permissível & $0,67-1$ & 0 & $1,33-2,0$ & 0 \\
Duvidoso & $1-1,25$ & 0 & $2,0-2,5$ & 0 \\
Inadequado & $>1,25$ & 0 & $>2,5$ & 0 \\
\hline
\end{tabular}

Tabela 5.Classificação da dureza das águas subterrâneas do município de Alegre (ES) de acordo com os critérios de Sawyer e McCarthy (2003).

\begin{tabular}{lll}
\hline DT $\left(\mathbf{m g ~ C a C O}_{3} \mathbf{L}^{-1}\right)$ & Classes de dureza & $\left(\mathbf{n}^{\circ}\right.$ de amostras $)$ \\
\hline$<75$ & Doce & $60(100 \%)$ \\
$75-150$ & Moderadamente dura & 0 \\
$150-300$ & Dura & 0 \\
$>300$ & Muito dura & 0 \\
\hline
\end{tabular}

A dureza alta pode causar incrustações nas tubulações usadas tanto para abastecimento de água, quanto para irrigação (AGRAWAL e JAGETAI, 1997). A classificação das águas subterrâneas da área de estudo com base na dureza foi realizada segundo os critérios de Sawyer e McCarthy (2003), (Tabela 5). Assim, as 60 amostras analisadas foram enquadradas na Classe 1 , sendo portanto consideradas Doces.

\section{CONCLUSÕES}

Nas condições em que a pesquisa foi conduzida, pode-se concluir que:

A água subterrânea estudada foi considerada imprópria para o consumo humano, devido ao fato de alguns parâmetros estarem em desacordo com a legislação (turbidez, $\mathrm{pH}$, bicarbonato e $\mathrm{Fe}^{3+}$ ) e, principalmente, pela presença de coliformes termotolerantes, que foram encontrados em todas as amostras analisadas.

Os valores de sólidos totais dissolvidos, condutividade elétrica e razão de adsorção de sódio estão dentro dos limites seguros para o uso na agricultura. Todas as amostras foram classificadas como $\mathrm{C}_{1} \mathrm{~S}_{1}$ e $\mathrm{C}_{2} \mathrm{~S}_{1}$, indicando baixa salinidade e baixo teor de $\mathrm{Na}^{+}$. Assim, á água subterrânea do município pode ser usada para irrigação em todos os tipos de solo sem risco de salinização.

Do ponto de vista sanitário, o uso da água subterrânea na irrigação por aspersão em hortaliças é impróprio devido à presença de coliformes termotolerantes.

Em todas as propriedades rurais visitadas, a água subterrânea utilizada oferece algum tipo de risco à saúde pública. O investimento em campanhas de conscientização e sensibilização através de educação sanitária e ambiental é premente para assegurar a qualidade de vida do homem no campo.

\section{REFERÊNCIAS}

ABNT - Associação Brasileira de Normas Técnicas. NBR 9898: Preservação e técnicas de amostragem de efluentes líquidos e corpos receptores. Rio de Janeiro, 1987.

AGRAWAL, V, JAGETAI, M. Hydrochemical assessment of groundwater quality in Udaipur city, Rajasthan, India. In: Proc. Indian Conference on Dimensions of Environmental Stress in India. Department of Geology, MS University, Baroda, India. p. 151- 154, 1997.

ALMEIDA, O. A. Qualidade da Água de Irrigação. Embrapa Mandioca e Fruticultura, Cruz das Almas, 1 ed., 2010.

AMERICAN PUBLIC HEATH ASSOCIATION APHA. Standard Methods for the Examination of 
Water and Wastewater. Washington DC, 21 th. ed., 2005.

AYERS, R. S.; WESTCOT, D. W. A qualidade da Água na Agricultura. 2.ed. Campina Grande: UFPB, FAO, Irrigação e Drenagem, 1999.

BONILHA, P. R. M.; FALCÃO, D. P. Ocorrência de enteropatógeno em alfaces e suas águas de irrigação. Alimentos e Nutrição, v. 5, p.87-97, 1993.

BOUCHARD, D. C.; WILLIAMS, M. D.; SURAMPALLI, R. Y. Nitrate contamination of ground water sources and potential health effects. Journal of the American Water Works Association, v.84, p.85-90, 1992.

BRASIL. MINISTÉRIO DA SAÚDE. Portaria n. 2914, de 12 de dezembro de 2011. Dispõe sobre os procedimentos de controle e de vigilância da qualidade da água para consumo humano e seu padrão de potabilidade. Diário Oficial da União, Brasília, p. 39, 12 dez. 2001.

BRASIL. MINISTÉRIO DO MEIO AMBIENTE. CONSELHO NACIONAL DO MEIO AMBIENTE. Resolução CONAMA no 396 , de 03 de abril de 2008. Diário Oficial da República Federativa do Brasil, Poder Executivo, Brasília, DF, 03 Abr. 2008. Seção Resoluções, 71 p., 2008.

ESRI. ArcGIS - ArcMap 10. Redlands: 15.

FEITOSA, F. A. C.; MANOEL FILHO, J. Hidrogeologia: Conceitos e Aplicações. Fortaleza: CPRM, LABHID - UFPE, ed. 2, 391 p., 2000.

IBGE. Produção da Pecuária Municipal 2009. Rio de Janeiro: IBGE, 2010.

ISSAC-MARQUEZ, A. P.; LEZAMA-DAVILA, C. M.; KU-PECH, R. P.; TAMAY-SEGOVIA, P. Calidad sanitaria de los suministros de agua para consumo humano en Campeche. Public Health of Mexico, v.36, p.655-661, 1994.

KUMAR, M.; KUMARI, K.; RAMANATHAN, A. L.; SAXENA, R. A comparative evaluation of groundwater suitability for irrigation and drinking purposes in two intensively cultivated districts of Punjab, India. Environmental Geology, v.53, p.553574, 2007.
MCCARTHY, T. S.; ELLERY, W. N. The effect of vegetation on soil and ground water chemistry and hydrology of islands in the seasonal swamps of the Okavango Fan, Botswana, Botswana. Journal of Hydrology, v.154, p.169-193, 1994.

NAGARAJAN, R.; RAJMOHAN, N.; MAHENDRAN, U.; SENTHAMILKUMAR, S. Evaluation of groundwater quality and its suitability for drinking and agricultural use in Thanjavur city, Tamil Nadu, India. Environmental Monitoring and Assessment, v.171, p.289308, 2010.

OBIEFUNA, G. I.; SHERIFF, A. Assessment of Shallow Ground Water Quality of Pindiga Gombe Area, Yola Area, NE, Nigeria for Irrigation and Domestic Purposes. Research Journal of Environmental and Earth Sciences, v.3, p.131-141, 2011.

PERCEBON, C. M.; BITTENCOURT, A. V. L. Considerações sobre as características de qualidade das águas subterrâneas de Blumenau - SC em relação à Resolução CONAMA 396. Águas Subterrâneas, v.23, p.69-84, 2009.

PURUSHOTHAM, D.; NARSING-RAO, A.; RAVIPRAKASH, M.; SHAKEEL-AHMED, S.; ASHOK BABU, G. Environmental Impact on Groundwater of Maheshwaram Watershed, Ranga Reddy District, Andhra Pradesh. Journal Geological Society of India, v.77, p.539-548, 2011

REDDY, A. G. S.; KUMAR, N. K. Identi $\square$ cation of the hydrogeochemical processes in groundwater using major ion chemistry: a case study of PennaChitravathi river basins in Southern India. Environmental Monitoring and Assessment, Holanda, v.170, p.365-382, 2010.

SAWYER, N. N.; McCARTY, P. L.; PARKIN, G. F. Chemistry for environmental engineering and science (5th edn.): McGraw-Hill, New York, 752 p., 2003.

SAWYER, G. N.; Mc CARTHY, D. L. Chemistry of Sanitary Engineers. 2.ed. New York: McGrawHill., 1967. 518p.

WHO. Nitrate and Nitrite in Drinking Water. Background Document for Development of WHO Guidelines for Drinking-water Quality. World Health Organization, WHO Press, 2006. 29p. 